\title{
Factors influencing vitamin D levels in women attending the fertility clinic and the effect on assisted fertility outcomes
}

\author{
Xuzhen Wang $^{1 *}$, Shaojie Zhao ${ }^{2 \#}$, Min Zhou ${ }^{1}$, Liping Jiang ${ }^{2}$ \\ ${ }^{1}$ Department of Breast Surgery, The Affiliated Wuxi Maternity and Child Health Care Hospital of Nanjing Medical University, Wuxi, China; \\ ${ }^{2}$ Department of Gynecology, The Affiliated Wuxi Maternity and Child Health Care Hospital of Nanjing Medical University, Wuxi, China \\ Contributions: (I) Conception and design: S Zhao; (II) Administrative support: X Wang; (III) Provision of study materials or patients: M Zhou; (IV) \\ Collection and assembly of data: L Jiang; (V) Data analysis and interpretation: X Wang; (VI) Manuscript writing: All authors; (VII) Final approval of \\ manuscript: All authors. \\ \#These authors contributed equally to this work. \\ Correspondence to: Liping Jiang. Department of Gynecology, The Affiliated Wuxi Maternity and Child Health Care Hospital of Nanjing Medical \\ University, Wuxi, China. Email: fckjlp1982@163.com.
}

\begin{abstract}
Background: Several factors affect vitamin D levels, such as sunshine, region, diet, obesity and so on. The primary objective of this study is to determine the prevalence of vitamin D deficiency (VDD) among infertile women in China and the contribution of VDD to the risk of infertility in women.

Methods: This single-center, retrospective case-control study included 2,456 infertile women. We investigated the vitamin $\mathrm{D}$ levels in all patients in the different seasons and across different ages. The clinical data of 411 patients who were in the assisted fertilization programs [in vitro fertilization (IVF) and ICSI] were also analyzed, as well as the correlation between vitamin D status and IVF clinical outcome.

Results: There were significant differences in 25-hydroxyvitamin D (25(OH)D) concentrations in different seasons $(\mathrm{P}<0.01)$. The proportions of severe VDD in spring, winter, summer, and autumn were $18.5 \%$, $18.6 \%, 7.8 \%$, and $8.8 \%$, respectively. The normal levels of $25(\mathrm{OH}) \mathrm{D}$ concentration $(50-74.9 \mathrm{nmol} / \mathrm{L})$ in summer, autumn, spring, and winter were $28.5 \%, 26.4 \%, 13.5 \%$, and $18.3 \%$, respectively. The $25(\mathrm{OH}) \mathrm{D}$ concentrations in 3 months (July, August, and September) had the highest levels, with levels over $40 \mathrm{nmol} / \mathrm{L}$ in these months. Compared with winter, the risk of severe VDD was lower in summer and autumn $(\mathrm{P}<0.01)$. Serum 25(OH)D concentration significantly correlated with female infertility.
\end{abstract}

Conclusions: Inference from these results shows that vitamin D may minimize the risk of female infertility and may be related to the seasons and age.

Keywords: Vitamin D; infertility; 25-hydroxyvitamin D; in vitro fertilization (IVF); seasons

Submitted May 10, 2021. Accepted for publication Jul 16, 2021.

doi: 10.21037/apm-21-1511

View this article at: https://dx.doi.org/10.21037/apm-21-1511

\section{Introduction}

Female infertility is a critical issue of global reproductive health, and the prevalence rate among child-seeking women is reported to be $9.3-16.7 \%$ (1). There are many etiologies of infertility in women, including abnormal ovulation, polycystic ovary syndrome (PCOS), fallopian tube problems, endometriosis (5-10\%) and unexplained causes (2). Infertility can result in depression, marital discordance, and family conflict, among other factors.

Vitamin D, a steroidal derivative, is also known as an anti-rickets vitamin. It is considered a steroid hormone, and the most important members of the vitamin $\mathrm{D}$ family are VD2 (ergocalciferol) and VD3 (cholecalciferol). Vitamin $\mathrm{D}$ is derived from these different members after ultraviolet irradiation (3). Plants lack vitamin $\mathrm{D}$ but pro-vitamin $\mathrm{D}$ is constituted in both animals and plants. Vitamin D is a fatsoluble vitamin, consisting of 5 compounds. Vitamin D2 
and vitamin D3 are the most important for human health (4). The 7-dehydrogenated cholesterol that is produced from cholesterol is stored under the skin of the human body and can be converted into vitamin D3 after being exposed to ultraviolet radiation. Adequate sunbathing has been thought to be sufficient to cater for the body's need for vitamin $\mathrm{D}$ (5). 25 -hydroxyvitamin D (25(OH)D) is the main form of vitamin $\mathrm{D}$ in the human body. Vitamin $\mathrm{D}$ is converted into $25(\mathrm{OH}) \mathrm{D}$ by hydroxylation in the liver, and then into the active 1,25-dihydroxy vitamin $\mathrm{D}$ in the kidney (6). Serum levels of $25(\mathrm{OH}) \mathrm{D}$ can reflect vitamin D storage levels and are associated with certain clinical symptoms of vitamin D deficiency (VDD) (3).

The fundamental roles of vitamin D are related to calcium metabolism and bone structure, as well as steroid hormones, and are well-known to most people (7). More and more evidence shows that vitamin $\mathrm{D}$ can regulate female reproductive processes. Biologically, the functions of vitamin $\mathrm{D}$ are mainly mediated by the vitamin $\mathrm{D}$ receptor (VDR) (8), which is expressed in many reproductive tissues, they include ovaries, uterus, testes and placenta (9). So scientists are paying close attention to the potential of vitamin $\mathrm{D}$ in preventing female infertility $(4,10)$.

In humans, some related articles have studied the relationship between serum $25(\mathrm{OH}) \mathrm{D}$ concentration in assisted reproductive technology and pregnancy rates $(11,12)$. Previous studies have shown that women with high serum vitamin $\mathrm{D}$ concentrations have a higher chance of getting pregnant, while VDD may affect the pregnancy rate of infertile women undergoing in vitro fertilization (IVF) or intracytoplasmic sperm injection $(13,14)$. However, the factors that affect the concentration of vitamin $\mathrm{D}$ in preventing infertility remain to be explored.

In this study, we investigated the correlations between vitamin D and infertility. Specifically, the present study looked at the relationship between vitamin $\mathrm{D}$ and female infertility among patients attending fertility clinics. Serum vitamin $\mathrm{D}$ was measured and associations were determined in relation to other fertility factors. We also looked at the effect of seasons on serum vitamin D levels. VDD, having been reported as one of the risk factors for female infertility, is estimated by serum $25(\mathrm{OH}) \mathrm{D}$ concentration levels. However, our results showed no direct effect of VDD in women in the fertility clinic. Also, this study reported on the significant effects of seasons and ages on serum levels in women in the fertility clinic. We present the following article in accordance with the STROBE reporting checklist (available at https://dx.doi.org/10.21037/apm-21-1511).

\section{Methods}

\section{Research object}

This study used a case-control method and was based on assessing the relationship between vitamin $\mathrm{D}$ and infertility in Chinese women. This study included women who went to the Fertility Clinic of the Affiliated Wuxi Maternity and Child Health Care Hospital of Nanjing Medical University for treatment of infertility from 2013 to 2019.

Except for infertility, none of the selected patients had a history or cure of serious underlying diseases such as cancer, cerebrovascular disease, trauma, liver, kidney, heart, respiratory system disease, chromosomal abnormality, etc. According to the standards of the World Health Organization, infertility is defined as not being pregnant or pregnant after unprotected intercourse for more than 12 months, regardless of whether it is eventually pregnant or not (15).

None of the participants had undergone hysterectomy at the time of recruitment, and each participant's written informed consent was obtained. The study protocol was approved by the Medical Ethics Committee of the Affiliated Wuxi Maternity and Child Health Care Hospital of Nanjing Medical University. All procedures performed in this study involving human participants were in accordance with the Declaration of Helsinki (as revised in 2013).

\section{Data collection}

Trained interviewers conducted face-to-face interviews with participants using standardized questionnaires to collect a range of information, including demographic factors (age, occupation, education, and family income), menstrual and reproductive history (age, menarche, pregnancy history, menopausal status and gynecological surgery), vitamin D supplementation within $30 \mathrm{~d}$, sun exposure, family history and lifestyle behaviors (including current drinking and smoking), etc. Medical information such as anthropometric variables (height and weight), contraceptive history, and gynecological examinations are also obtained from the patient's medical records.

\section{Serum 25(OH)D measurements}

Take $10 \mathrm{~mL}$ blood samples from each participant, centrifuge to separate serum and plasma, and store at $-80{ }^{\circ} \mathrm{C}$ until analysis

Serum $25(\mathrm{OH}) \mathrm{D}$ was measured by radioimmunoassay 
Table 1 Characteristics of serum $25(\mathrm{OH}) \mathrm{D}$, age groups, and infertility

\begin{tabular}{|c|c|c|c|c|}
\hline Subgroup & $n$ & \multicolumn{2}{|c|}{ Serum 25(OH)D (nmol/L) } & $P$ \\
\hline Age & & & & 0.021 \\
\hline $21-25$ & 293 & 37.5 & $29.2-49.5$ & \\
\hline $26-30$ & 1,352 & 36.8 & $29.0-47.5$ & \\
\hline A history of infertility & & & & 0.21 \\
\hline Primary infertility & 2,251 & 37.5 & 29.3-48.2 & \\
\hline Secondary infertility & 205 & 40.7 & $29.0-51.5$ & \\
\hline Total & 2,456 & 37.5 & $29.3-48.5$ & \\
\hline
\end{tabular}

(RIA) according to the manufacturer's instructions $(25(\mathrm{OH})$ total vitamin D-RIA-CT, DIA source Immuno Assays, Nivelles, Belgium). The intra- and inter-assay coefficients of variations $(\mathrm{CV})$ were $<6 \%$ and $<10 \%$, respectively. Vitamin D levels $[25(\mathrm{OH}) \mathrm{D}$ concentration] were categorized as follows: normal levels as $50-74.9 \mathrm{nmol} / \mathrm{L}$, VDD as $<50 \mathrm{nmol} / \mathrm{L}$, and severe deficiency as $<25 \mathrm{nmol} / \mathrm{L}$.

\section{Statistical analysis}

The main results of this study were the prevalence of VDD among infertile women in China and the contribution of VDD to the risk of female infertility. $\mathrm{P}$ values $<0.05$ were considered statistically significant; hence, $\mathrm{Z} 1-\mathrm{a}=1.96$ was used in the formula. Sample size was calculated with precision/absolute error (d) of 5\%. Data were presented as mean \pm SD for continuous variables, and as frequencies or percentages for categorical variables. The Wilcoxon ranksum test and $\chi^{2}$ tests were used to determine any statistical difference among the groups. The distribution of $25(\mathrm{OH}) \mathrm{D}$ in cases and controls is presented using median and interquartile range (IQR). The Wilcoxon nonparametric test was used to compare the $25(\mathrm{OH}) \mathrm{D}$ serum concentration differences between cases and controls.

We performed an unconditional logistic regression to calculate the odds ratio $(\mathrm{OR})$ as an estimate of the relative risk and its $95 \%$ confidence interval (CI) in order to clarify the relationship between the serum $25(\mathrm{OH}) \mathrm{D}$ concentration and take into account the exposure to the disease The relationship may not be linear or monotonous. Finally, according to these definitions, the $25(\mathrm{OH}) \mathrm{D}$ concentration is divided into two categories: VDD $(<50 \mathrm{nmol} / \mathrm{L})$, normal level (50-74.9 nmol/L) and severe deficiency ( $<25 \mathrm{nmol} / \mathrm{L})$. Following our univariate analysis and previous research, these variables were considered as potential confounding factors and were adjusted in multivariate logistic regression: age, education, household income, sun exposure, parity, and vitamin D supplementation within $30 \mathrm{~d}$. And our data showed that most women did not drink alcohol and smoke. Hence, these two variables were not considered for adjustment.

\section{Results}

\section{Characteristics and vitamin D levels across the study population}

This study investigated the vitamin D levels in 2,456 infertile women, with an average age of $29.1 \pm 3.2$, within the age range of 21-35 years old. The median vitamin D levels were $37.5 \mathrm{nmol} / \mathrm{L}$ [interquartile range (IQR), 29.3-48.5] and $40.7 \mathrm{nmol} / \mathrm{L}$ (IQR, 29.0-51.5) in the primary and secondary infertility groups, respectively (Table 1). The vitamin D level of $<25 \mathrm{nmol} / \mathrm{L}$ was $13.6 \%$, the level of $25-$ $49.9 \mathrm{nmol} / \mathrm{L}$ was about $63.7 \%$, the level of $50-74.9 \mathrm{nmol} / \mathrm{L}$ was $20.9 \%$, and the level of $75 \mathrm{nmol} / \mathrm{L}$ and greater was only $1.8 \%$ in infertile women (Table 2).

\section{Seasonal characteristics of vitamin D levels}

Our research showed significant differences in vitamin D levels across the different seasons, namely winter, spring, summer, and autumn. The median vitamin $\mathrm{D}$ levels in summer, autumn, spring, and winter were 42.3, 40.8, 34.5, 
Table 2 Characteristics of various categories of serum $25(\mathrm{OH}) \mathrm{D}$ with age groups and infertility

\begin{tabular}{|c|c|c|c|c|c|c|}
\hline Subgroup & $\mathrm{n}$ & \multicolumn{4}{|c|}{ Serum 25(OH)D (nmol/L), n (\%) } & $P$ \\
\hline \multicolumn{7}{|l|}{ Age } \\
\hline $21-25$ & 293 & $39(13.3)$ & $184(62.8)$ & 65 (22.2) & $5(1.7)$ & 0.112 \\
\hline $26-30$ & 1,352 & $197(14.6)$ & $871(64.4)$ & $265(19.6)$ & $19(1.4)$ & \\
\hline \multicolumn{7}{|l|}{ A history of infertility } \\
\hline Primary infertility & 2,251 & $304(13.5)$ & $1,447(64.3)$ & $462(20.5)$ & $38(1.7)$ & 0.262 \\
\hline Secondary infertility & 205 & $31(15.1)$ & $117(57.1)$ & $51(24.9)$ & $6(2.9)$ & \\
\hline Total & 2,456 & $335(13.6)$ & $1,564(63.7)$ & $513(20.9)$ & $44(1.8)$ & - \\
\hline
\end{tabular}

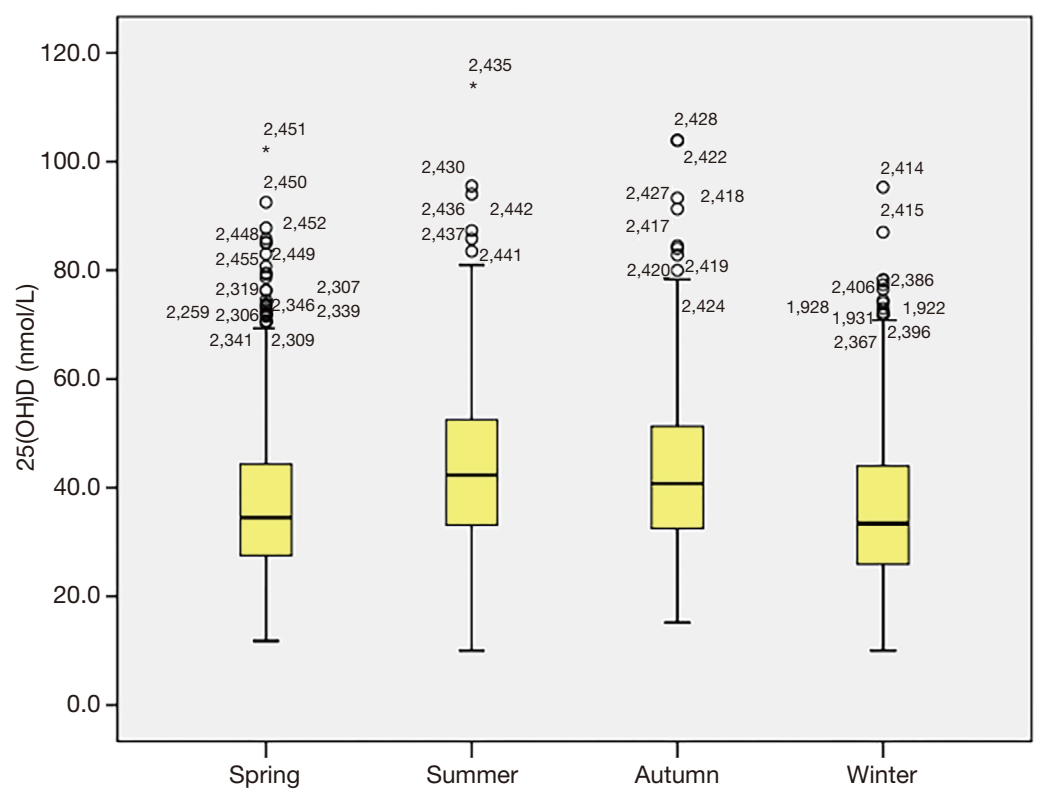

Figure 1 A graph showing vitamin D levels of participants measured in the various seasons. The months of July, August, and September showed relatively higher levels of vitamin D (* stands for data bias).

and $33.4 \mathrm{nmol} / \mathrm{L}$, respectively $(\mathrm{P}<0.05$, Figure 1$)$. The proportions of severe VDD in spring, winter, summer, and autumn were $18.5 \%, 18.6 \%, 7.8 \%$, and $8.8 \%$. Acceptable levels of vitamin D must be within the range of 50 to $74.9 \mathrm{nmol} / \mathrm{L}$. In summer, autumn, spring, and winter, $28.5 \%, 26.4 \%, 13.5 \%$, and $18.3 \%$, respectively, were reported to fall within the acceptable levels in the study group $(\mathrm{P}<0.05$, Figure 2). Monthly comparisons of these levels were also estimated. There were significant differences in the vitamin $\mathrm{D}$ levels in different months. The vitamin D levels in July, August, and September showed the highest levels, with the levels all over $40 \mathrm{nmol} / \mathrm{L}(\mathrm{P}<0.05$, Figure 3).

Additionally, the proportion of severely deficient patients was $13.6 \%(<25 \mathrm{nmol} / \mathrm{L})$, the proportion of deficient and severely deficient patients altogether was $77.3 \%$ $(<50 \mathrm{nmol} / \mathrm{L})$, and the proportion of patients whose vitamin D levels were less than $75 \mathrm{nmol} / \mathrm{L}$ was $98.2 \%$. Compared with the winter season, the risk of severe VDD was lower in the summer and autumn seasons $(\mathrm{P}<0.001$, Figure 3$)$, 


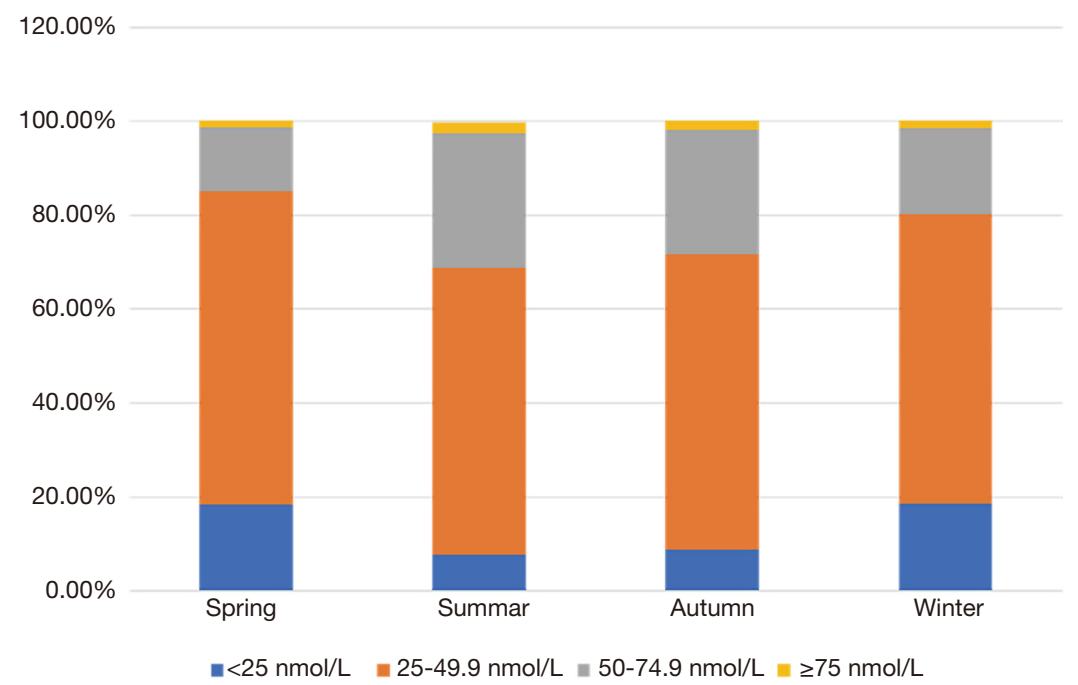

Figure 2 A graph showing the percentage of participants and their vitamin D levels in the various seasons. Each bar is stratified to reflect the various categories of vitamin D levels. A greater percentage of participants with adequate vitamin D levels were measured in summer and autumn.

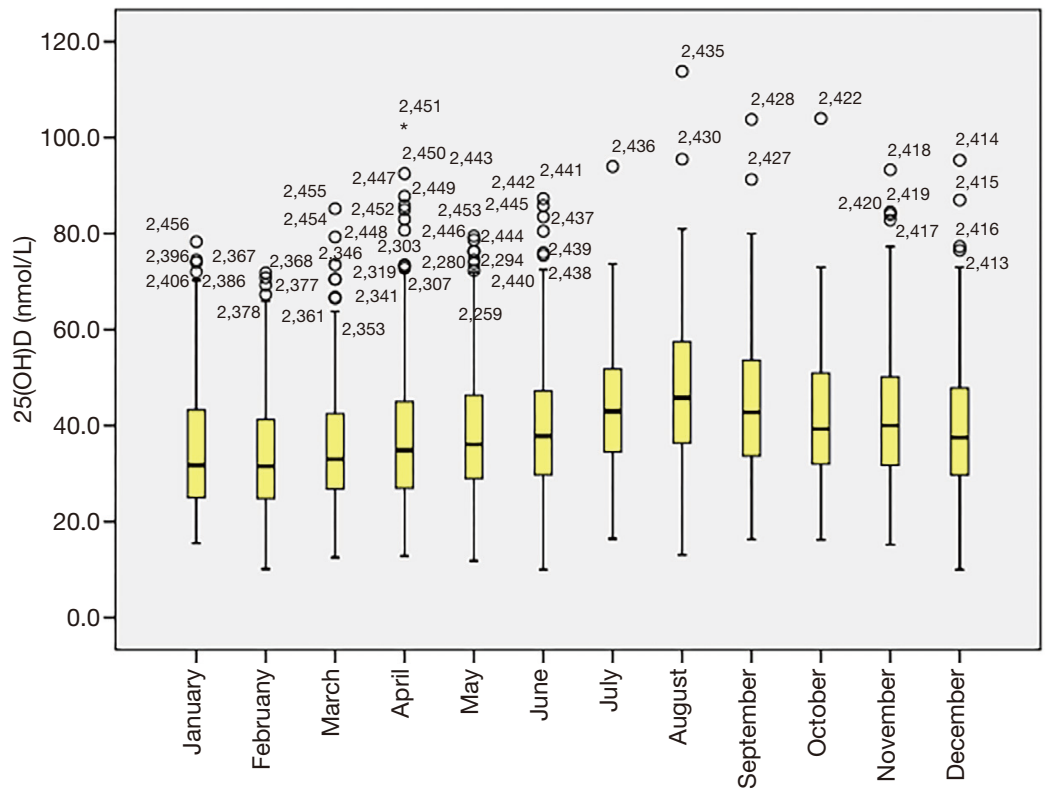

Figure 3 A graph showing vitamin D levels of participants measured in the various months. The months of July, August, and September showed relatively higher levels of vitamin $\mathrm{D}$ (* stands for data bias).

and there was no significant difference in the spring season. Other basic data are shown in Table 3.

\section{Age affects vitamin D levels}

This study also reported the effects of different age groups on vitamin D levels in the study population. Interestingly, there were significant differences in vitamin D levels among the different age groups $(\mathrm{P}<0.021$, Table 1$)$. The median vitamin $\mathrm{D}$ levels were as follows: $37.5 \mathrm{nmol} / \mathrm{L}$ among 21-25 years old, $36.8 \mathrm{nmol} / \mathrm{L}$ among $26-30$ years old, and 
Table 3 Prevalence of various serum 25(OH)D categories with the respective seasons

\begin{tabular}{|c|c|c|c|c|c|}
\hline & $n$ & Prevalence (\%) & Odds ratio & $95 \% \mathrm{Cl}$ & $P$ value \\
\hline Season & 2,456 & 13.6 & & & \\
\hline Spring & 785 & 17.1 & 0.781 & $0.587-1.04$ & 0.091 \\
\hline Summer & 575 & 7.8 & 0.322 & $0.222-0.468$ & $<0.001$ \\
\hline Winter & 494 & 20.9 & 1 & & \\
\hline \multicolumn{6}{|l|}{$<50 \mathrm{nmol} / \mathrm{L}$} \\
\hline Season & 2,456 & 77.3 & & & \\
\hline Spring & 785 & 84.5 & 1.129 & $0.834-1.529$ & 0.431 \\
\hline Winter & 494 & 82.8 & 1 & & \\
\hline \multicolumn{6}{|l|}{$<75 \mathrm{nmol} / \mathrm{L}$} \\
\hline Season & 2,456 & 98.2 & & & \\
\hline Spring & 785 & 98.3 & 0.607 & $0.215-1.714$ & 0.346 \\
\hline Summer & 575 & 97.6 & 0.410 & $0.147-1.146$ & 0.089 \\
\hline Autumn & 602 & 98.0 & 0.503 & $0.176-1.437$ & 0.503 \\
\hline Winter & 494 & 99.0 & 1 & & \\
\hline
\end{tabular}

$38.5 \mathrm{nmol} / \mathrm{L}$ among $31-35$ years old. However, there was no significant difference in vitamin $\mathrm{D}$ levels among the different age groups. Likewise, there were no significant differences in vitamin $\mathrm{D}$ levels between primary and secondary infertility groups $(\mathrm{P}=0.21$, Table 1$)$.

\section{Effects of vitamin $D$ in patients undergoing assisted fertilization programs (IVF and ISI)}

The clinical data of 411 patients who were in the assisted fertilization programs (IVF and ISI) were analyzed, as well as the correlation between vitamin D status and IVF clinical outcome. The 411 patients were divided into a vitamin $\mathrm{D}$ deficient or severely deficient group $[25(\mathrm{OH}) \mathrm{D}$ $<50 \mathrm{nmol} / \mathrm{L}]$ and vitamin $\mathrm{D}$ suitable or sufficient group $[25(\mathrm{OH}) \mathrm{D} \geq 50 \mathrm{nmol} / \mathrm{L}]$. The mean ages of the two groups were $29.80 \pm 3.88$ and $29.72 \pm 3.76$ years old, respectively, and were not significantly different. The percentages of success in outcome (i.e., pregnancy) were $59.7 \%, 49.1 \%$, $49.3 \%$, and $75 \%$ in patients with vitamin D levels $<25,25-$
49.9, 50-74.5, and $>75 \mathrm{nmol} / \mathrm{L}$, respectively. Comparing the clinical outcomes of fresh-cycle transplantation in the two groups, the high-quality embryo ratios of the VDD or severely deficient group and the vitamin D suitable or sufficient group were $48.6 \%$ and $46.3 \%(\mathrm{P}=0.319)$, respectively. The HCG endometrial thicknesses of the VDD or severely deficient group and the vitamin D suitable or sufficient group were $11.37 \pm 2.07$ and $1.85 \pm$ $0.36 \mathrm{~cm}(\mathrm{P}=0.311)$, respectively. Also, the clinical pregnancy rates of the VDD or severely deficient group and the vitamin D suitable or sufficient group were $51.1 \%$ and $51.9 \%$, respectively $(\mathrm{P}=0.893)$. The embryo implantation rate of the vitamin D suitable or sufficient group was $37 \%$ and was higher than the VDD or severely deficient group with $29.9 \%$. However, there were no significant differences between the two groups $(\mathrm{P}=0.098)$ in all these parameters. Other characteristics of the data are shown in Table 4. The overall outcomes of the IVF and ISI procedures were also not significant among the various categories of vitamin D levels as well as when compared seasonally. 
Table 4 Anthropometric measurements and characteristics of patients who underwent assisted fertilization programs in the various seasons with vitamin $\mathrm{D}$ level below or higher than $50 \mathrm{nmol} / \mathrm{L}$

\begin{tabular}{lccc}
\hline Characteristic & $<50 \mathrm{nmol} / \mathrm{L}(\mathrm{N}=332)$ & $\geq 50 \mathrm{nmol} / \mathrm{L}(\mathrm{N}=79)$ & $\mathrm{P}$ \\
\hline Age $(\mathrm{yrs})$ & $29.80 \pm 3.88$ & $29.72 \pm 3.76$ & 0.864 \\
$\mathrm{BMI}\left(\mathrm{kg} / \mathrm{m}^{2}\right)$ & $22.27 \pm 3.12$ & $21.71 \pm 2.80$ & 0.149 \\
$\mathrm{AMH}(\mathrm{ng} / \mathrm{mL})$ & $5.41 \pm 3.72$ & $5.01 \pm 2.81$ & 0.675 \\
Duration of infertility $(\mathrm{yrs})$ & $3.79 \pm 2.51$ & $3.71 \pm 2.37$ & 0.784 \\
Season & & & 0.730 \\
Spring & $79.5 \%(70 / 88)$ & $20.5 \%(18 / 88)$ & \\
Summer & $77.8 \%(56 / 72)$ & $22.2 \%(16 / 72)$ & $20.5 \%(18 / 88)$ \\
Autumn & $79.5 \%(70 / 88)$ & $16.7 \%(28 / 168)$ \\
Winter & $83.3 \%(140 / 168)$ &
\end{tabular}

$\mathrm{AMH}$, anti-Mullerian hormone.

\section{Discussion}

Vitamin D is one of the most important steroid hormones in the body. It plays the most important role in mineral homeostasis and regulation as well as bone formation through calcium and phosphorus metabolism $(16,17)$.

Under general circumstances, most vitamin D could cater for the human body's need by self-synthesis, and only a little amount of vitamin D is obtained from diet $(4,10)$. The human body's synthesis of vitamin D starts within the skin. When skin cells are exposed to the sun's ultraviolet rays, they convert cholesterol into 7-dehydrogencholesterol (3,16-18). An inactive precursor, vitamin D3, is derived from the 25-hydroxylation of cytochrome $\mathrm{P} 450$ in the liver to produce calcitriol $[25(\mathrm{OH}) \mathrm{D}]$. After binding with circulating vitamin D binding protein (DBP), calcitriol is catalyzed by another cytochrome P450 enzyme and 1 alpha-hydroxylase in the kidney to form the active vitamin D metabolite calcitriol [1,25-2 hydroxyvitamin D3, 1,25 (OH) 2D] $(15,19,20)$. Ultimately, calcitriol works through the VDR. Vitamin D exerts biological effects in the body mainly by binding to the VDR. VDR is a nucleophile protein belonging to the superfamily of the steroid hormone receptor which mediates the expression of the active component of vitamin $\mathrm{D}$, namely 1, 25-dihydroxy vitamin D $(21,22)$. With the participation of other ligands, VDR regulates calcium as well as phosphorus metabolism in vivo.

Vitamin D and its receptors' mechanisms are as follows: they raise the expression of insulin-like growth factor (IGF) binding protein, reduce the activity of IGF, and block the mitosis of IGF-1 $(22,23)$. Vitamin D, by raising the cyclin-dependent kinase inhibitors (CDKI) P21 and P27, inhibits the activity of periodic element (cyclin) i.e., cyclindependent kinase (CDK) complexes. C-Myc is a gene of translocation and an important factor involved in cell cycle regulation. Vitamin D, however, promotes the tyrosine phosphorylation of the $\mathrm{c}-\mathrm{Myc}$ protein and accelerates the ubiquitination and degradation of the c-Myc protein (24).

Vitamin D is essential in the body for regulating calcium and phosphorus metabolism, and is useful in preventing and treating rickets $(3,4,7,16-18)$. Since its receptors are almost everywhere in various tissues and organs in the body, vitamin D has more extensive extracellular biological effects, such as regulating immunity, anti-tumor effects, protecting the central nervous system, as well as preventing and controlling metabolic syndrome (5,6,25). Many researchers have reported that vitamin D levels and a variety of diseases are closely related to each other. For instance, infantile respiratory tract infection, asthma, osteoporosis, a variety of autoimmune diseases, kidney disease, cardiovascular diseases, preeclampsia, allergic asthma, rheumatoid arthritis, type I or II diabetes, dementia, and infectious diseases (3-6,25-27), as well as some kinds of tumors, have all been implicated in VDD. The effects of vitamin D levels on different diseases have also been the focus of research in recent years.

Infertility refers to men and women of childbearing age who live together for more than 1 year, have a normal sex life, have never taken any contraceptive measures, and still fail to conceive $(11,28-30)$. There are many factors 
that may be involved in infertility. However, females have been the main target when trying to deal with infertility. In the analysis of female infertility factors, a large number of research data has confirmed that there are many factors affecting female infertility. According to previous reports, the number of female infertility patients is about $14.5 \%$ of the population within childbearing age, and secondary infertility accounts for about two-thirds, and this trend keeps increasing year by year. In regards to the leading etiological causes, pelvic factors in secondary infertility account for the first, ovulation factors account for the second, and immune factors and other reasons account for a small proportion $(13,14)$. In traditional Chinese families, the situation of infertility can lead to a dissatisfied sexual life, problems within the family, divorces, and many other unpleasant outcomes. Therefore, it is important that patients with infertility are examined at the hospital in time to be able to determine the cause, and timely treatment of various endocrine system diseases is provided. Most patients with this condition actively cooperate with drug treatments and follow the doctor's advice on a reasonable diet and active intervention.

Having understood the role of vitamin D in the body, and particularly the reproductive system, this research sought to provide some answers as to its link to female infertility by understanding the levels of vitamin $\mathrm{D}$ in women with infertility attending fertility clinics. Recent research has focused on the role of vitamin $\mathrm{D}$ concentrations in female infertility. Based on data reported in various systematic reviews and meta-analyses of cohort studies and also the results from our 2,456 women in this study, the association between vitamin $\mathrm{D}$ status and infertility has been established. Particularly, this study is the first to report on the variations in vitamin $\mathrm{D}$ levels across the seasons. From our data, the high vitamin D level during summer could be the result of increased exposure to the sun due to the warm weather and the higher likelihood that the sun comes into direct contact with the skin. The reverse could be explained for the low levels during winter and spring, where most people are likely to reduce their exposure to outside conditions as a result of the cold weather. This observation was corroborated when we analyzed the data by month. The results showed significant increases in July, August, and September, which happen to be the warm months, and as explained previously, likely lead to increased skin exposure to sunlight.

The results of investigating the effect of VDD on the outcome of patients who underwent the IVF or ICSI procedure showed no significant effect on the outcome i.e., pregnancy. This could be the result of the small number of patients analyzed for this outcome. It is also common knowledge that the procedure for IVF entails a complex medication system that could impact the body's natural processes. Therefore, assessing this condition could have many confounders whose impact could be direct or indirect.

According to the Italian Association of Clinical Endocrinologists (AME) and the Italian Chapter of American Association of Clinical Endocrinologists (AACE), serum vitamin $\mathrm{D} 3$ values $>20 \mathrm{ng} / \mathrm{mL}(50 \mathrm{nmol} / \mathrm{L})$ can be considered appropriate, in the general population, with recommended levels $>30 \mathrm{ng} / \mathrm{mL}(31,32)$. The results of this present study demonstrate that VDD is a risk factor for infertility in women. VDD seems to independently affect female fertility. Combining the current results with previous literature, we can deduce that adequate vitamin $\mathrm{D}$ might reduce the risk of infertility in women of reproductive ages. We suggest using either vitamin D2 or vitamin D3 for the treatment and prevention of vitamin $\mathrm{D}$ deficiency We suggest that all adults who are vitamin D deficient be treated with 50,000 IU of vitamin D2 or vitamin D3 once a week for $8 \mathrm{wk}$ or its equivalent of 6,000 IU of vitamin D2 or vitamin D3 daily to achieve a blood level of $25(\mathrm{OH}) \mathrm{D}$ above $30 \mathrm{ng} / \mathrm{mL}$, followed by maintenance therapy of $1,500-2,000 \mathrm{IU} / \mathrm{d}$. There is no evidence that there is a downside to increasing vitamin D intake in children and adults, except for those who have a chronic granuloma-forming disorder or lymphoma (32).

However, a large number of prospective studies and clinical trials are still needed to assess the causal relationship between adequate vitamin $\mathrm{D}$ and other factors that contribute to infertility. This study also reveals the seasonal changes in vitamin D levels in infertile women, which can be further explored to offer better treatments in terms of vitamin $\mathrm{D}$ supplementation in particular seasons.

\section{Conclusions}

Inference from these results shows that adequate amounts of vitamin D may minimize the risk of female infertility and may be related to the seasons and age.

\section{Acknowledgments}

The authors are indebted to the donors, whose names were not included in the author list, but who participated in this program.

Funding: This work was supported by Science and 
Technology Development Fund of Wuxi City, Innovation and Application Project of Medical and Public Health Technology (No. N20202020).

\section{Footnote}

Reporting Checklist: The authors have completed the STROBE reporting checklist. Available at https://dx.doi. org/10.21037/apm-21-1511

Data Sharing Statement: Available at https://dx.doi. org/10.21037/apm-21-1511

Conflicts of Interest: All authors have completed the ICMJE uniform disclosure form (available at https://dx.doi. org/10.21037/apm-21-1511). The authors have no conflicts of interest to declare.

Ethical Statement: The authors are accountable for all aspects of the work in ensuring that questions related to the accuracy or integrity of any part of the work are appropriately investigated and resolved. The Ethical Committee of the Affiliated Wuxi Maternity and Child Health Care Hospital of Nanjing Medical University approved the present study. All patients provided signed informed consent. All procedures performed in this study involving human participants were in accordance with the Declaration of Helsinki (as revised in 2013).

Open Access Statement: This is an Open Access article distributed in accordance with the Creative Commons Attribution-NonCommercial-NoDerivs 4.0 International License (CC BY-NC-ND 4.0), which permits the noncommercial replication and distribution of the article with the strict proviso that no changes or edits are made and the original work is properly cited (including links to both the formal publication through the relevant DOI and the license). See: https://creativecommons.org/licenses/by-nc-nd/4.0/.

\section{References}

1. Inal ZO, Inal HA, Gorkem U. Sexual function and depressive symptoms in primary infertile women with vitamin D deficiency undergoing IVF treatment. Taiwan J Obstet Gynecol 2020;59:91-8.

2. Templeton A. Infertility and the establishment of pregnancy-overview. Br Med Bull 2000;56:577-87.

3. Wang Q, Yu D, Wang J, et al. Association between vitamin D deficiency and fragility fractures in Chinese elderly patients: a cross-sectional study. Ann Palliat Med 2020;9:1660-5.

4. van der Leeuw C, de Witte L, Stellinga A, et al. Vitamin D concentration and psychotic disorder: associations with disease status, clinical variables and urbanicity. Psychol Med 2020;50:1680-6.

5. Jahn D, Dorbath D, Kircher S, et al. Beneficial effects of vitamin $\mathrm{D}$ treatment in an obese mouse model of nonalcoholic steatohepatitis. Nutrients 2019;11:77.

6. Ni LH, Yuan C, Song KY, et al. Efficacy and safety of cinacalcet and active vitamin $\mathrm{D}$ in the treatment of secondary hyperparathyroidism in patients with chronic kidney disease: a network meta-analysis. Ann Transl Med 2019;7:322.

7. Panda DK, Miao D, Tremblay ML, et al. Targeted ablation of the 25-hydroxyvitamin D 1 $\alpha$-hydroxylase enzyme: evidence for skeletal, reproductive, and immune dysfunction. Proc Natl Acad Sci U S A 2001;98:7498-503.

8. Johnson LE, DeLuca HF. Vitamin D receptor null mutant mice fed high levels of calcium are fertile. J Nutr 2001;131:1787-91.

9. Kinuta K, Tanaka H, Moriwake T, et al. Vitamin D is an important factor in estrogen biosynthesis of both female and male gonads. Endocrinology 2000;141:1317-24.

10. Wang JR, Yu Q, Dai W, et al. Drug-drug co-crystallization presents a new opportunity for the development of stable vitamins. Chem Commun (Camb) 2016;52:3572-5.

11. Ciepiela P, Dulęba AJ, Kowaleczko E, et al. Vitamin D as a follicular marker of human oocyte quality and a serum marker of in vitro fertilization outcome. J Assist Reprod Genet 2018;35:1265-76.

12. Abadia L, Gaskins AJ, Chiu YH, et al. Serum 25-hydroxyvitamin $\mathrm{D}$ concentrations and treatment outcomes of women undergoing assisted reproduction. Am J Clin Nutr 2016;104:729-35.

13. Anifandis GM, Dafopoulos K, Messini CI, et al. Prognostic value of follicular fluid 25-OH vitamin D and glucose levels in the IVF outcome. Reprod Biol Endocrinol 2010;8:91.

14. Neville G, Martyn F, Kilbane M, et al. Vitamin D status and fertility outcomes during winter among couples undergoing in vitro fertilization/intracytoplasmic sperm injection. Int J Gynaecol Obstet 2016;135:172-6.

15. Bikle DD, Schwartz J. Vitamin D binding protein, total and free vitamin D levels in different physiological and pathophysiological conditions. Front Endocrinol (Lausanne) 2019;10:317. 
16. Yakah W, Fenton JI, Sikorskii A, et al. Serum Vitamin D is Differentially Associated with Socioemotional Adjustment in Early School-Aged Ugandan Children According to Perinatal HIV Status and In Utero/Peripartum Antiretroviral Exposure History. Nutrients 2019;11:1570.

17. Hill TR, Verlaan S, Biesheuvel E, et al. A Vitamin D, Calcium and Leucine-Enriched Whey Protein Nutritional Supplement Improves Measures of Bone Health in Sarcopenic Non-Malnourished Older Adults: The PROVIDE Study. Calcif Tissue Int 2019;105:383-91.

18. Roy A, Ray R. Aminopropylation of vitamin D hormone (1 , 25-dihydroxyvitamin D3), its biological precursors, and other steroidal alcohols: An anchoring moiety for affinity studies of sterols. Steroids 1995;60:530-3.

19. Al-Daghri NM, Mohammed AK, Bukhari I, et al. Efficacy of vitamin D supplementation according to vitamin D-binding protein polymorphisms. Nutrition 2019;6364:148-54.

20. Gao Y, Zhou S, Luu S, et al. Megalin mediates 25-hydroxyvitamin D3 actions in human mesenchymal stem cells. FASEB J 2019;33:7684-93.

21. Maj E, Trynda J, Maj B, et al. Differential response of lung cancer cell lines to vitamin $\mathrm{D}$ derivatives depending on EGFR, KRAS, p53 mutation status and VDR polymorphism. J Steroid Biochem Mol Biol 2019;193:105431.

22. Montenegro KR, Cruzat V, Carlessi R, et al. Mechanisms of vitamin $\mathrm{D}$ action in skeletal muscle. Nutr Res Rev 2019;32:192-204.

23. Singhal V, Ackerman KE, Bose A, et al. Impact of route of estrogen administration on bone turnover markers in oligoamenorrheic athletes and its mediators. J Clin Endocrinol Metab 2019;104:1449-58.

24. Malinen M, Saramäki A, Ropponen A, et al. Distinct HDACs regulate the transcriptional response of human cyclin-dependent kinase inhibitor genes to trichostatin A and 1 $\alpha, 25$-dihydroxyvitamin D3. Nucleic Acids Res 2008;36:121-32.

25. Milajerdi A, Ostadmohammadi V, Amirjani S, et al. The

Cite this article as: Wang $\mathrm{X}$, Zhao $\mathrm{S}$, Zhou M, Jiang L. Factors influencing vitamin $\mathrm{D}$ levels in women attending the fertility clinic and the effect on assisted fertility outcomes. Ann Palliat Med 2021;10(7):7813-7822. doi: 10.21037/apm-21-1511 effects of vitamin D treatment on glycemic control, serum lipid profiles, and C-reactive protein in patients with chronic kidney disease: a systematic review and metaanalysis of randomized controlled trials. Int Urol Nephrol 2019;51:1567-80.

26. Bivona G, Sasso BL, Iacolino G, et al. Standardized measurement of circulating vitamin D [25 (OH) D] and its putative role as a serum biomarker in Alzheimer's disease and Parkinson's disease. Clin Chim Acta 2019;497:82-7.

27. Bromage S, Enkhmaa D, Baatar T, et al. Comparison of seasonal serum 25-hydroxyvitamin D concentrations among pregnant women in Mongolia and Boston. J Steroid Biochem Mol Biol 2019;193:105427.

28. Maes K, Serré J, Mathyssen C, et al. Targeting vitamin D deficiency to limit exacerbations in respiratory diseases: utopia or strategy with potential? Calcif Tissue Int 2020;106:76-87.

29. Missailidis C, Sørensen N, Ashenafi S, et al. Vitamin D and Phenylbutyrate Supplementation Does Not Modulate Gut Derived Immune Activation in HIV-1. Nutrients 2019; 11:1675.

30. Fabris A, Pacheco A, Cruz M, et al. Impact of circulating levels of total and bioavailable serum vitamin $\mathrm{D}$ on pregnancy rate in egg donation recipients. Fertil Steril 2014;102:1608-12.

31. Cesareo R, Attanasio R, Caputo M, et al. Italian Association of Clinical Endocrinologists (AME) and Italian Chapter of the American Association of Clinical Endocrinologists (AACE) Position Statement: Clinical Management of Vitamin D Deficiency in Adults. Nutrients 2018;10:546.

32. Holick MF, Binkley NC, Bischoff-Ferrari HA, et al. Evaluation, treatment, and prevention of vitamin D deficiency: an Endocrine Society clinical practice guideline. J Clin Endocrinol Metab 2011;96:1911-30. Erratum in: J Clin Endocrinol Metab 2011;96:3908.

(English Language Editor: C. Betlazar-Maseh) 